fournal of Medical Genetics (1973). 10, 294-304.

\section{Trisomy 13 in Two Infants with Cyclops*}

Summary. Two infants with cyclops malformation were born at the University of Southern California Medical Center during the past three years. The karyotypes of both infants demonstrated an extra chromosome No. 13: one with $47, \mathrm{XX},+13$ and one with $46, X X,-14,+t(13 q 14 q)$. The physical findings, karyotypes with trypsin-Giemsa banding, and association of trisomy 13 syndrome with cyclops malformation are presented.

The cyclops malformation is a rare developmental anomaly characterized by fusion of the optic vesicle with a proboscis-like structure above the orbit. We are aware of 15 reported cases of cyclops in whom chromosome analyses were done. Of these, six showed trisomy D (Toews and Jones, 1968; Arakaki and Waxman, 1969; Halbrecht et al, 1971 ; Batts et al, 1972; Golob, Schaller, and KunzeMühl, 1972; Taysi and Tinaztepe, 1972), two had deleted short arms of chromosome No. 18 (Faint and Lewis, 1964; Nitowsky et al, 1966), one had an 18 ring (Cohen, Storm, and Capraro, 1972), one had mosaicism of normal cells and cells with an extra chromosome (Pfitzer, 1967), one had mosaicism of normal cells and monosomy G (Cohen, 1966), and the remaining four had normal karyotypes (Harnden, Jacobs, and Buckton, 1961 ; Juberg, 1966; Lejeune, 1966; Lieber et al, 1970).

Classification of cyclops into two different groups was suggested by DeMyer (1964) and Taysi and Tinaztepe (1972). Cyclops in the first group is thought to be causally related to trisomy $\mathrm{D}$, presumably trisomy 13 . This group shows the extra-

Received 7 May 1973.

* This study was supported in part by Grant No. 286 from Maternal and Child Health Service, United States Public Health Service. cephalic malformations characteristic of trisomy 13 in addition to cyclopia. In one case, the trisomic $\mathrm{D}$ chromosomes were identified as Nos. 13 by autoradiography (Arakaki and Waxman, 1969). The second group is comprised of the remaining cases of cyclopia resulting from other chromosomal aberrations, single gene mutations, and other genetic and non-genetic factors.

This is a report of the physical and cytogenetic findings in two infants with cyclops born at our medical centre in the last three years.

\section{Case Reports}

Case 1. The patient was born at term after an uncomplicated pregnancy and delivery to healthy, unrelated parents. The mother, gravida III, para II, Ab 0 , was 26 years old and the father was 34 . They have two normal sons. The mother is of German-Polish descent and the father is Irish. There is no family history of congenital malformation.

Physical examination at birth revealed a female infan weighing $2675 \mathrm{~g}$ and measuring $45 \mathrm{~cm}$ in length. The head and chest circumferences were each $28 \mathrm{~cm}$. The

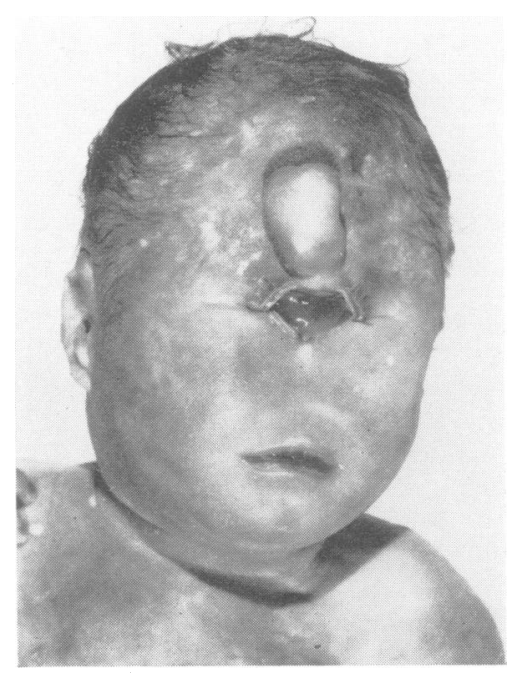

FIG. 1. Case 1 with typical facies of cyclopia. 
face had a centrally placed, diamond-shaped orbit lying below a tubular appendage measuring $2.5 \mathrm{~cm}$ in length (Fig. 1). The ears were normal. There were rudimentary sixth digits on each hand and on the left foot. The infant expired one hour after birth.

At the necropsy examination two closely placed eyes ( $5 \mathrm{~mm}$ ) were found in the single orbit. The tubular appendage contained a single cavity that ended blindly where it attached to the head. There were no fontanelles. The base of the skull was smaller than normal and a single frontal bone, $3.5 \mathrm{~cm}$ in diameter was found. The cerebrum consisted of a central lobe and two smaller lateral lobes. The cerebellum was small and elongated. The olfactory and optic nerves could not be identified. Additionally, there were a high interventricular septal defect, a probe-patent foramen ovale, ectopic splenic tissue $(2 \times 0.7 \times 0.5 \mathrm{~cm})$ in the tail of pancreas, and increased fetal lobulation of the kidneys. The external genitalia were normal female in appearance but there was a wart-like appendage located on the anterior portion of each of the labia minora.

Case 2. The patient was born to a 21-year-old, gravida II, para 0, Ab I Mexican-American mother and a Mexican-American father of unknown age, both recent immigrants from Mexico. The pregnancy was complicated by mild pre-eclampsia during the last month which was treated with chlorothiazide. The length of the gestation was unknown. The previous pregnancy resulted in a spontaneous abortion during the fifth month.

Physical examination at birth revealed a $2900 \mathrm{~g}$ infant who was $49 \mathrm{~cm}$ in length. The head circumference was $26 \mathrm{~cm}$ and the chest circumference was $32 \mathrm{~cm}$. Two

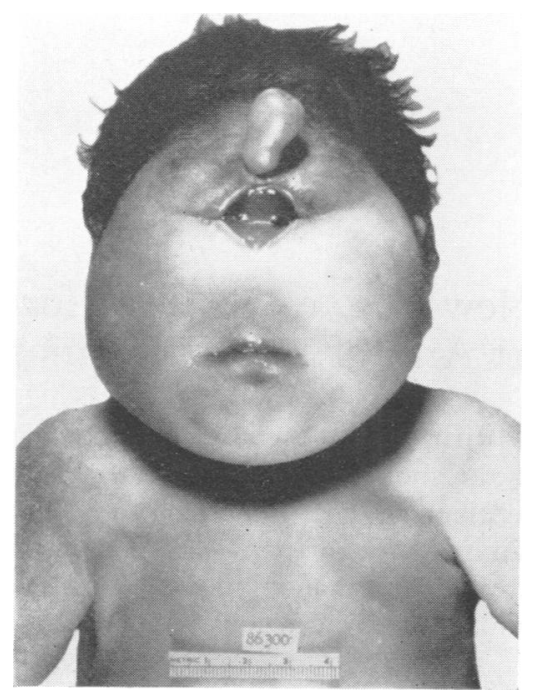

FIG. 2. Case 2 with cyclopia almost identical to case 1. eyes were seen in the diamond shaped orbit. A tubular appendage was located centrally above the orbit (Fig. 2). There was a rudimentary digit arising laterally from the fifth digit of the left hand. The infant expired 30 minutes after birth.

At the necropsy examination the frontal bone was noted to be hypoplastic with no anterior fossa. The right petrous ridge had cystic changes. The brain showed aplasia of the frontal lobes with fusion of the hemispheres. The cerebellum appeared normal. The

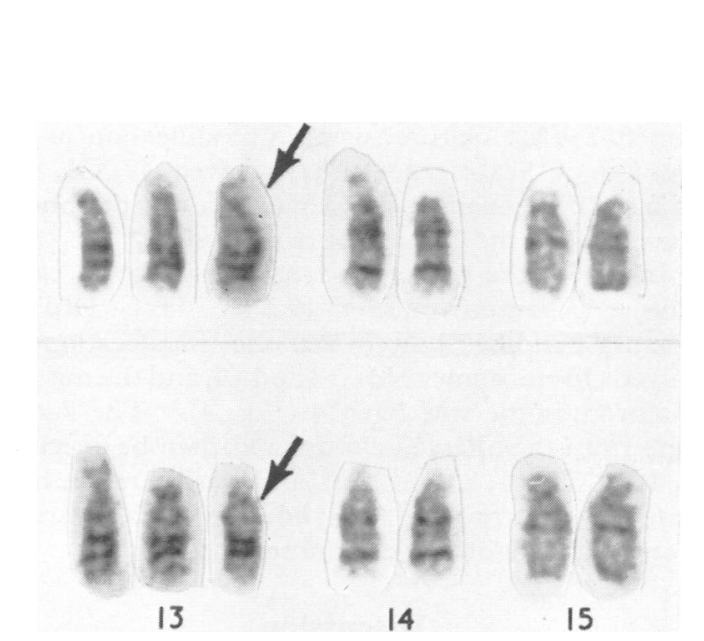

FIG. 3. Giemsa banding of partial karyotype of D-group chromosomes from case 1. The arrow indicates trisomy 13. (Fibroblast culture.)

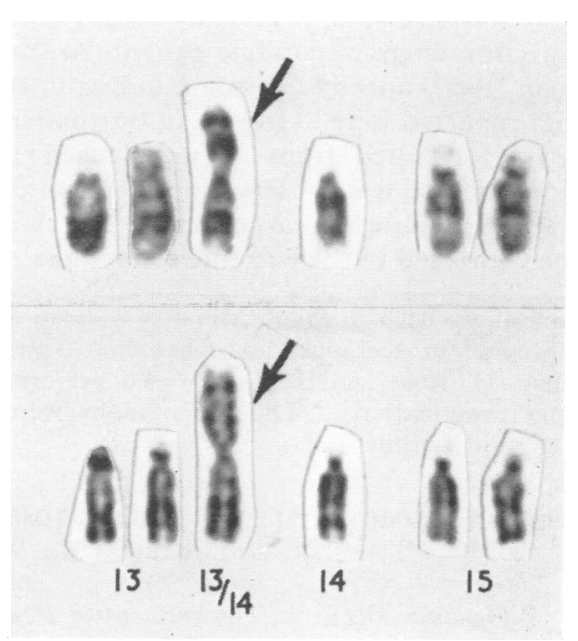

Fig. 4. Giemsa banding of partial karyotype of D-group chromosomes from case 2 . The arrow indicates $13 \mathrm{q} 14 \mathrm{q}$ translocation. (Peripheral blood culture.) 
heart was markedly dilated with a hypertrophic right ventricle. The tricuspid valve had only two leaflets. The foramen ovale was probe patent and the ductus arteriosus was open. Additionally, there was a Meckel's diverticulum and markedly hyperlobulated kidneys. The external genitalia were normal in appearance but the vagina showed a marked cobblestone mucosa.

\section{Cytogenetic Studies}

Cytogenetic studies from case 1 included cultures of peripheral blood and skin fibroblasts. Karyotypes from both cultures showed trisomy $\mathrm{D}(47, \mathrm{XX},+\mathrm{D})$. Giemsa banding of cells from the skin fibroblast culture, using a modification of the method of Seabright (1971), showed 47,XX, +13 (Fig. 3). Chromosome analysis of peripheral leucocytes of the parents were normal.

In case 2 the karyotype from a peripheral blood culture demonstrated 46,XX, $-\mathrm{D},+\mathrm{t}(\mathrm{DqDq})$. Giemsa banding showed that the translocation involved chromosomes Nos. 13 and 14, and the missing D chromosome was No. 14 (Fig. 4). The karyotype from the affected child could then be specified as $46, \mathrm{XX},-14,+\mathrm{t}(13 \mathrm{q} 14 \mathrm{q})$, and was therefore consistent with trisomy 13 syndrome. The parents were not available for chromosome study.

\section{Discussion}

Including the present study, an extra D chromosome or unbalanced DqDq translocation has been reported in eight of 17 cytogenetic studies of infants with cyclopia. All of these eight infants had extracephalic malformations of trisomy 13 phenotype in addition to cyclopia. Trisomy 13 has been verified by autoradiography in one patient (Arakaki and Waxman, 1969) and by Giemsa banding in the two patients reported here. In one of our patients the trisomy 13 resulted from an unbalanced 13q14q translocation. These observations confirm that the faciocerebral malformations of trisomy 13 syndrome may be expressed in the extreme as cyclopia.

The authors wish to thank Mrs Fay Kaplan and Mr Paul Brager for technical assistance and Drs A. L. Wittman, M. Rose, and R. Silton who performed the necropsy examinations. The photographs were taken by Mr David Larkin.

Atsuko Fujimoto, Allan J. EbBin, Joseph W. TOWNER, and Miriam G. WILSON

Genetics Division, Department of Pediatrics, University of Southern California School of Medicine, Los Angeles, California 90033, USA

\section{REFERENCES}

Arakaki, D. T. and Waxman, S. H. (1969). Trisomy D in a cyclops. fournal of Pediatrics, 74, 620-622.

Batts, J. A., Jr., Punnett, H. H., Valdes-Dupena, M., Coles, J. W., and Green, W. R. (1972). A case of cyclopia. American fournal of Obstetrics and Gynecology, 112, 657-661.

Cohen, M. M. (1966). Chromosomal mosaicism associated with a case of cyclopia. Fournal of Pediatrics, 69, 793-798.

Cohen, M. M., Storm, D. F., and Capraro, V. J. (1972). A ring chromosome (No. 18) in a cyclops. Clinical Genetics, 3, 249-259. DeMyer, W. (1964). A 46 chromosome cebocephaly with remarks on the relation of 13-15 trisomy to holoprosencephaly (arhinencephaly). Annales Paediatrici, 203, 169-177.

Faint, S. and Lewis, F. J. W. (1964). Personal communication.

Golob, E. Schaller, A., and Kunze-Mühl, E. (1972). Zyclopie. mit D-trisomie. Wiener klinische Wochenschrift, 84, 272-275.

Halbrecht, I., Kletzky, O., Komlos, L., Lotker, M., and Gersht, N. (1971). Trisomy-D in cyclops. Obstetrics and Gynecology, 37, 391-393.

Harnden, D. G., Jacobs, P. A., and Buckton, K. E. (1961). Personal communication. In Sohval, A. R. Recent progress in human chromosome analysis and its relation to the sex chromatin. American fournal of Medicine, 31, 397-441.

Juberg, R. C. (1966). Personal communication. In Cohen, M. M. Chromosomal mosaicism associated with a case of cyclopia. Fournal of Pediatrics, 69, 793-798.

Lejeune, J. (1966). Personal communication. In Cohen, M. M. Chromosomal mosaicism associated with a case of cyclopia. fournal of Pediatrics, 69, 793-798.

Lieber, E., Hsu, L. Y, F., Gertner, M., Strauss, L., and Hirschhorn, K. (1970). Cytogenetic studies in holoprosencephaly. (Abstr.) Program and Abstracts, p. 126. The American Pediatrics Society and the Society for Pediatric Research.

Nitowsky, H. M., Sindhvananda, N., Konigsberg, U. R., and Weinberg, T. (1966). Partial 18 monosomy in the cyclops malformation. Pediatrics, 37, 260-269.

Pfitzer, P. (1967). Extra minute chromosome in cyclops. Lancet, 2, 102-103.

Seabright, M. (1971). A rapid banding technique for human chromosomes. Lancet, 2, 971-972.

Taysi, K. and Tinaztepe, K. (1972). Trisomy D and the cyclops malformation. American fournal of Diseases of Children, 124, 710 713.

Toews, H. A. and Jones, H. W. (1968). Cyclopia in association with $\mathrm{D}$ trisomy and gonadal agenesis. American fournal of Obstetrics and Gynecology, 102, 53-56.

\section{A New Case of Trisomy for the Short Arm of No. 9 Chromosome}

Summary. A new case with trisomy for the short arm of No. 9 chromosome, identified by heat treatment and Giemsa staining is reported. The clinical picture and dermatoglyphic patterns are similar to those previously reported.

Received 10 April 1973. 